\title{
A metapopulation of the lizard Anguis fragilis (Squamata: Anguidae) on a local scale in Dorset, Great Britain, as indicated by spatial distribution and movement
}

\author{
Thomas Haley \\ Bournemouth University, Talbot Campus, Poole, UK. E-mail: thomasdavidhaley@gmail.com.
}

\begin{abstract}
A metapopulation of the lizard Anguis fragilis (Squamata: Anguidae) on a local scale in Dorset, Great Britain, as indicated by spatial distribution and movement. A metapopulation is a group of spatially structured populations, consisting of distinct units (subpopulations) that are separated by space or barriers, and connected by dispersal movements. Evidence derived from Gaussian finite-mixture models and dispersal events suggests that slow-worms may exist in a metapopulation. The Gaussian finite-mixture models showed that slow-worms are aggregated into individual subpopulations; the movement data revealed that males are more likely to migrate than females and that they have the ability to travel sufficiently far to bridge subpopulations. Therefore, the evidence supports the metapopulation theory and that slow-worms exist in multiple small subpopulations instead of one large homogenous population.
\end{abstract}

Keywords: dispersal, male bias, mark-recapture, slow-worm.

\begin{abstract}
Resumo
Uma metapopulação em escala local para o lagarto Anguis fragilis (Squamata: Anguidae) em Dorset, Grã-Bretanha, revelada pela distribuição espacial e movimentação. Uma metapopulação pode ser definida como uma população espacialmente estruturada, consistindo em unidades distintas (subpopulação) separadas por espaços ou barreiras e conectadas por movimentos de dispersão. Objetivamos fornecer evidências de que o lagarto Anguis fragilis poderia potencialmente existir em uma metapopulação usando modelos de misturas finitas de gaussianas e eventos de dispersão. Esses modelos mostraram que os lagartos estavam agregados em subpopulações individuais, enquanto os dados de movimentação mostraram que os machos têm maior probabilidade de migrar e a capacidade para atravessar distâncias suficientes para interligar subpopulações. Portanto, as evidências suportam a teoria de metapopulações e a de que Anguis fragilis vive em múltiplas pequenas subpopulações, em vez de em uma grande população homogênea.
\end{abstract}

Palavras-chave: desvio para machos, dispersão, lagarto, marcação-recaptura.

Received 7 August 2014.

Accepted 2 December 2014.

Distributed December 2014. 


\section{Introduction}

Recent surveys conducted by the National Amphibian and Reptile Record Scheme (NARRS) demonstrated that the slow-worm, Anguis fragilis Linnaeus, 1758, is distributed nationwide in the UK. It is unclear whether localized populations are continuously distributed within a single habitat or isolated in preferred sections within a habitat. Slow-worms prefer damp meadows and exist in aggregated distributions in areas with a range of different microhabitats (Platenberg 1999, Ryan 2008). However, the distribution of slow-worms within the same habitat type is not clear. The aim of this study is to ascertain whether slow-worms naturally cluster within preferred habitat types, and migrate among the clusters; if so, slowworms may represent a localized metapopulation. Previous studies reported that slow-worms can travel up to $34 \mathrm{~m}$ in a day, and Geiser et al. (2013) suggested that this distance is undervalued and that dispersal could be much farther. Thus, if slow-worms naturally aggregate within the same habitat type and are capable of migrating among aggregations, the population may be a smallscale metapopulation.

Any species that exists in a metapopulation must have some mechanism for dispersal; if not, the population will suffer from inbreeding depression (Hanski and Thomas 1994, Hanski 1999). Platenberg and Griffiths' (1999) empirical study on the translocation of slow-worms, from development sites to colonized areas have shown that introduced individuals have a reduced fitness. This suggests that inter-populational migration is minimal and dispersal among subpopulations may be limited, thereby enhancing isolation among slow-worm subpopulations. Consequently, observation of the movements of individual slow-worms are important to conservation or population-management efforts with the species. Moreover, documentation of a metapopulation would be vital to conservation measures if the population is surviving in a fragmented landscape (Ter Braak 1998). The presence of aggregations within a homogeneous area may signal the existence of a metapopulation. Gaussian finite-mixture models were used to identify subpopulations within the population of each site.

Migration is a key feature of a metapopulation. An understanding of dispersal may help identify the most likely individuals to re-colonize suitable patches (Hanski 1994, Driscoll 2007); thus, a mark-recapture method was used to chart individual slow-worm movements.

\section{Materials and Methods}

The catch-and-release project was conducted at two sites in Dorset, UK (Site1 XY coordinates X50 52.739 Y1 51.566, Site 2 XY coordinates X50 45.224 Y1 55.159). Site 1 (Noon Hill; Figure 1A) is a homogeneous, open grassland, bordered by a small, wooded area along the northeast edge of the site; heathland occurs north of the site, but not used in this study. Site 2 (Turbary Common; Figure 1B) is a heathland habitat intersected by small footpaths, and surrounded by dense gorse, which was inaccessible to study. Data collection was performed in a 30-day period in April 2012; each survey was conducted at 10:00am until all refugia were checked, usually before 12:00am. To limit disturbance, survey visits to any refugium were separated by 72 hours; thus, each site was surveyed 10 times. Slow-worms commonly bask under stones and other refugia; therefore, artificial refugia were used to capture individuals (Riddell 1996, Ferreiro and Galan 2004). A total of 279 artificial refugia were placed at a stratified random distribution on each site with 154 on Site 1 and 125 on Site 2. Each artificial refugium was assigned a GPS reference number (with a Garmin GPSMAP 62 to an accuracy of $\leq 5 \mathrm{~m}$ ) to record slow-worm movements (Reading 1997). The presence of each individual slowworm was record under each refugia to provide presence/absence data.

Movement within a single population of slow-worms was monitored by a capture-and- 
release method (Ferreiro and Galan 2004, Zimmerman et al. 2011). Each individual captured in a sample site was identified with photographic imagery, following the protocol of Platenberg and Griffiths (1999); all images were processed manually to identify each individual by the scales and markings of the head and chin samples. The recapture frequency for each individual also was recorded, along with a GPS reference for the location of capture. The number of recaptures of the same individuals within an area will reveal any migration among subpopulations and if the subpopulations constitute a larger metapopulation (Zimmerman et al. 2011).

The sex of each individual caught was recorded to determine whether gender was related to migration behavior. Male and female slow-worms have sexually dimorphic colorations (Stumpel 1985, Smith 1990). Adult males are more or less uniform in color with lighter markings and may have blue flecks. Adult females have dark flanks that are distinct from the dorsum, which usually is brown; females also have smaller heads size and more slender bodies. Because the sex of juvenile slow-worms cannot be determined, they were not included in the results. Slow-worms were classified as adults if the snout-vent length (SVL) was greater than $130 \mathrm{~mm}$ (Platenberg 1999). A $t$-test was used to analyze difference in movement between the sexes.

A Gaussian finite-mixture model was used to test for data partitions in the GPS reference points of slow-worm locations. Mclust program in $\mathrm{R}$ was used to identify the best Gaussian finite-mixture model according to Bayesian Information Criterion (BIC; Schwarz 1978). The most appropriate model to use was the one that has the largest BIC score (Andrews and McNicholas 2012); this criterion has been used for model selection in model-based clustering by many theoretical and applied studies (Leroux 1992, Kass and Raftery 1995, Kass and Wasserman 1995, Keribin 2000, Andrews and McNicholas 2012).

\section{Results}

\section{Clustering}

The results from finite mixture models reveal that populations of slow-worms are not evenly distributed and naturally separate into clusters. Multiple models were used to identify the model with the best fit to the data; Table 1 shows the BIC scores for the models used. In Site 1, a total of 35 slow-worms was caught, with 19 being found multiple times. The best model used for the Site 1 was VII (spherical, varying volume) with two clusters $(\mathrm{BIC}=303.4025$; Figure 2A). In Site 2, a total 36 slow worms was caught with, 15 being found multiple times; the EII (spherical, equal volume) model is the most appropriate model, with three clusters being identified $(\mathrm{BIC}=163.9512$; Figure 2B).

\section{Movement}

We recaptured 34 slow-worms from 71 $(47.9 \%$; males $=22$; females $=12)$ individuals during a 30-day period. Distance was calculated from the location of last capture to the next, irrespective of time. Males moved a significantly greater distances than did females $\left(\mathrm{t}_{(55.293)}=\right.$ $2.720 ; p=0.009$; Figure 3 ). There is a bias towards male movement because the males are more likely to disperse than females. However recapture rate is low; of the 34 lizards that were recaptured, there was an average of 1.44 captures per lizard during the 30-day period.

\section{Discussion}

For the pupose of this study, a metapopulation was defined as a spatially structured population consisting of distinct units (subpopulations), separated by space or barriers, and connected by dispersal movements (Opdam 1991). The results showed that slow-worms have aggregated distributions with sporadic migration among subpopulations in a homogenous habitat. Therefore, on a localized scale, slow-worms 

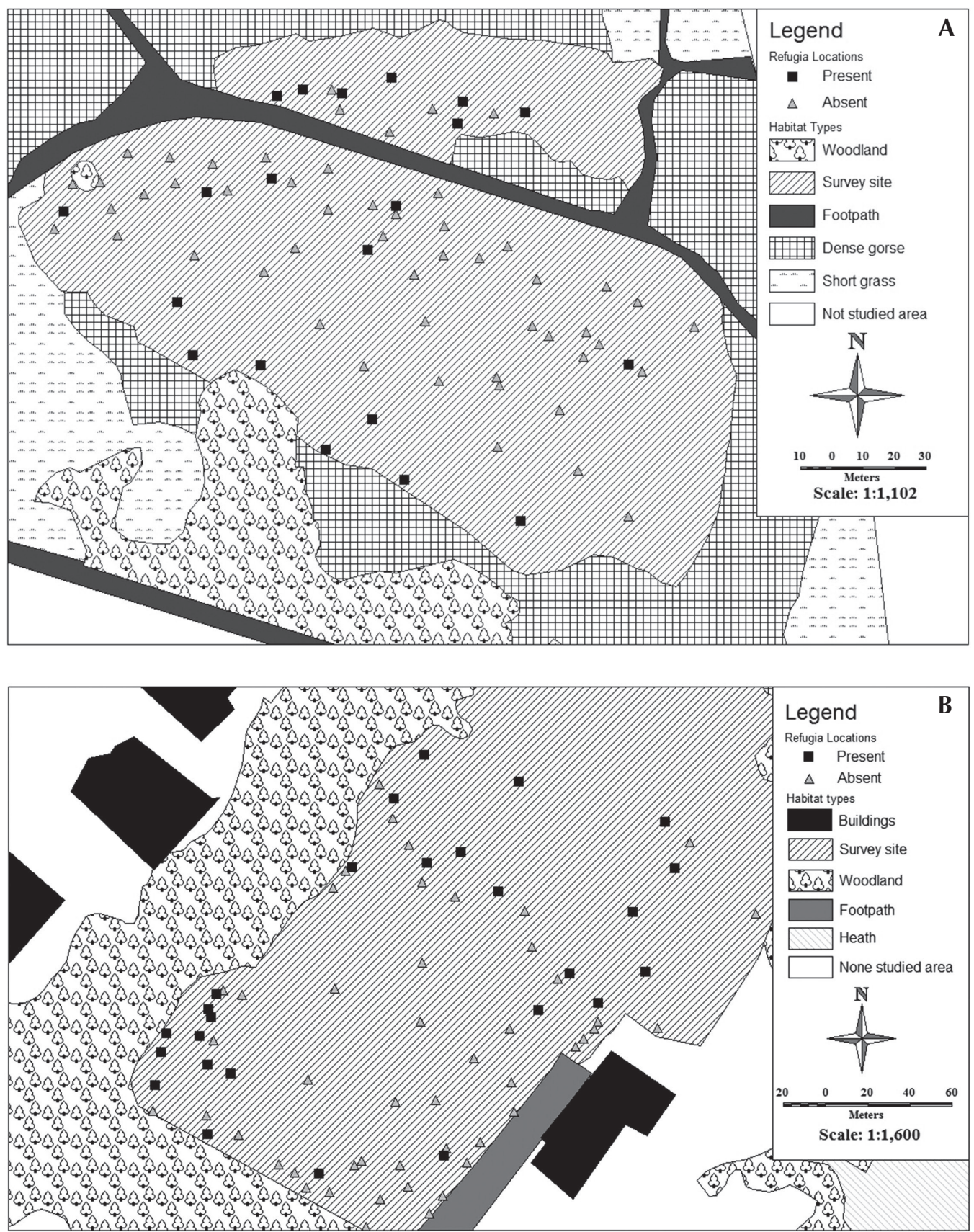

Figure 1. (A) Map of Site 1 showing survey site with surrounding habitat types and present/absent locations. The site is a wet grassland surrounded by small woodlands and a dense heathland to the north. An abandoned house is located east of the Site. (B) Map of Site 2 showing survey site with surrounding habitat types and refugia locations. The survey Site is small heathland surrounded by dense gorse, except in the south where there is a small wooded area. To the east is a large area of short grassland. 

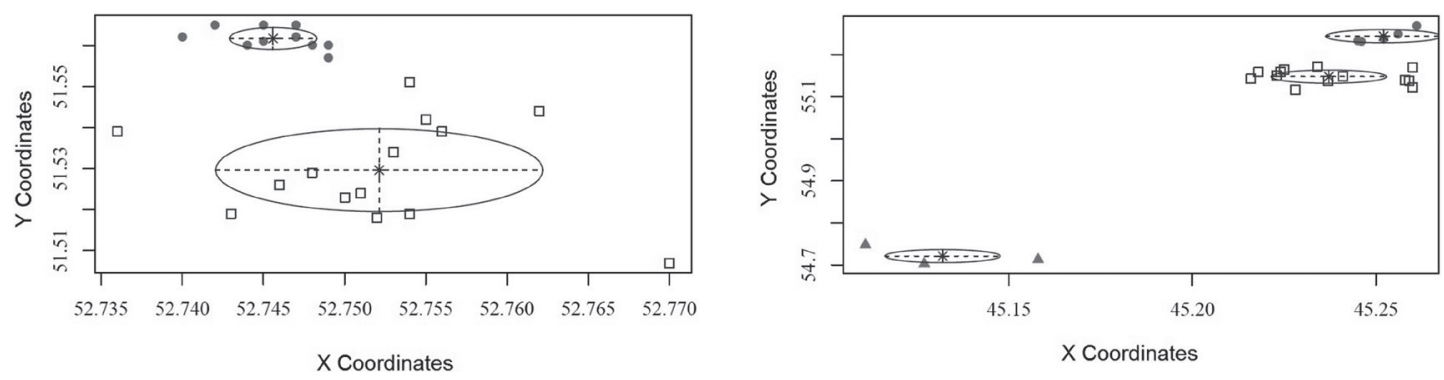

Figure 2. Clustering in Sites 1 and 2 from the Gaussian finite-mixture model. The $X$ and $Y$ coordinates show the position of individual slow-worms at each site. Circles signify the first cluster; squares, the second, and triangles the third cluster. The mean area of each cluster is plotted in (A) as output from VII (spherical, varying volume) model with two components on Site 1 and (B) as output from Ell (spherical, equal volume) model with three components in Site 2.

Table 1. BIC scores from each model used both sites. The highest BIC score identifies which model is most appropriate. "EII": spherical, equal volume, "VII": spherical, unequal volume, "EEI": diagonal, equal volume and shape, "VEI": diagonal, varying volume, equal shape, "EVI": diagonal, equal volume, varying shape, "VVI": diagonal, varying volume and shape, "EEE": ellipsoidal, equal volume, shape, and orientation, "EEV": ellipsoidal, equal volume and equal shape.

\begin{tabular}{cccccccccc}
\hline Site & $\begin{array}{c}\text { Number } \\
\text { of clusters }\end{array}$ & EII & VII & EEI & VEI & EVI & VVI & EEE & EEV \\
\hline Site 1 & 2 & 283.679 & $\mathbf{3 0 3 . 4 0 2 5}$ & 282.8607 & 301.1647 & 279.6919 & 299.762 & 296.6616 & 296.8549 \\
Site 2 & 3 & $\mathbf{1 6 3 . 9 5 1 2}$ & 160.8686 & 161.0606 & 158.5176 & 156.1487 & 154.8759 & 158.8122 & 155.0219 \\
\hline
\end{tabular}

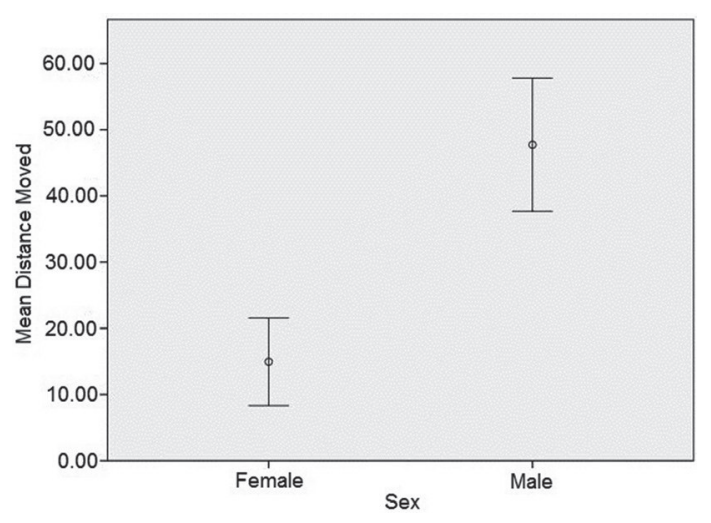

Figure 3. Mean results of distance moved by 34 slowworms (males $=22$; females $=12$ ) in a 30-day period. Males have a significantly higher $\left(\mathrm{t}_{(55.293)}=2.720, p=0.009\right)$ movement distance than do females. Error bars: $\pm 1 \mathrm{SE}$. conform to the metapopulation theory. Given the brevity of this project, we only could provide a snapshot of the spatial distribution and migration. To identify a metapopulation unequivocally, localized extinction and recolonization events must occur, and be documented by longer-term data set.

The Gaussian finite-mixture models suggest that slow-worms are divided into subpopulations across a uniform habitat. The reasons for these aggregations are unclear because in reptiles such as slow-worms, cues often are subtle and difficult to identify. Gonzalo et al. (2004) showed that males use scent deposits to locate females and did not avoid other males, thereby suggesting that males are not especially territorial. Thus, subpopulations may form as males locate groups 
of basking females. The results indicate that slow-worms may function as a small-scale metapopulation by naturally forming a network of small subpopulations across a homogenous habitat. Being distributed in a small-scale metapopulation may become increasingly important to the survival of slow-worms as habitat availability decreases. A network of subpopulations could be more easily sustained than many small, independent populations in the face of diminishing habitat. As habitat loss increases, there is greater pressure for protected areas to support a different mosaic of habitats to increase localized biodiversity. The biodiversity of a conserved area can be increased with the understanding that slow-worms exist in a metapopulation, because these lizards require less optimum habitat and can subsist in a heterogeneous area with multiple habitat types. However, this requires that dispersal channels are created between suitable sites (e.g., gardens) to link subpopulations (Geiser et al. 2013).

Male slow-worms are more likely to disperse than females, possibly because the viviparous females tend to aggregate at favorable basking sites. Studies have shown that thermal conditions affect both the rate at which the embryo develops and the phenotypic traits of the neonates in viviparous lizards (Schwarzkopf and Shine 1991, Shine and Harlow 1993, Wapstra 2000). Thermal conditions also affect the timing of the birth for each offspring, which, in turn, affects the fitness of the offspring in a viviparous lizard (Niveoscincus ocellatus; Wapstra et al. 2010). As males do not bear this cost, they can afford to be nomadic with a higher dispersal potential. Consequently, males are more likely to roam and link subpopulations together. Identifying areas that are accessible and not already occupied by a subpopulation of male slow-worms would benefit translocation practice. As shown in the study by Platenberg and Griffiths (1999), current translocation guidelines have a negative effect on the fitness of individual slow-worms; however, the difference in effect on the sexes is unclear. Therefore, increasing connectivity between translocated populations could increase the ability for a subpopulation to assimilate into the larger population.

Dispersal corridors are vital in the conservation of any organism that exists in a metapopulation. Because male slow-worms have a higher potential to disperse, they would be the predominant users of dispersal corridors within slow-worm populations. This has some applied benefits related to future conservation practices, and male slow-worms could be used as a proxy for identifying the use of dispersal corridors between subpopulations.

The resilience of slow-worms that enables them to live in a diversity of habitats may account for their widespread distribution. Nonetheless, connectivity among subpopulations is an important area for conservation. Metapopulations depend on localized extinction and recolonization events to survive, but without connectivity, recolonization cannot occur and subpopulations are more prone to extinction. Although males are more likely to disperse, there is a higher potential that interaction between a male and a random dispersal event from a female may result in recolonization. Previous research on slow-worms has shown that they are capable of travelling large distances and that dispersal events could be under represented (Geiser et al. 2013). The same study also showed that slowworms can migrate over areas that were previously thought to be impassable, further supporting the theory that slow-worms exist in a metapopulation (Geiser et al. 2013). For future conservation of the slow-worm, creating dispersal channels to promote a larger network of subpopulations would encourage recolonization and reduce the decline in British populations.

\section{Acknowledgments}

I thank the personnel at the ARC trust and Bournemouth Borough Council for granting access to the sites. Special thanks are extended to Kathy H. Hodder, John Wilkinson, Gary Powell, Steve Clarke, Renata Platenberg, 
Richard Griffiths, Anne Riddell, and Madeleine Ryan. I also am grateful to volunteers who helped collect data-Colette Cherry, David Fletcher, Ross Wheeler, Sean Graham, Kirti Ramash, Lee Plater, Alice Hicks, and Nathan Lewis-Hans Olsen.

\section{References}

Andrews, J. and P. McNicholas. 2012. Model-based clustering, classification, and discriminant analysis via mixtures of multivariate t-distributions. Statistics and Computing 22: 1021-1029.

Arnold, E. N., J. A. Burton, and D. W. Ovenden. 1978. A Field Guide to the Reptiles and Amphibians of Britain and Europe. London. Collins. 120 pp.

Driscoll, D. A. 2007. How to find a metapopulation. Canadian Journal of Ecology 85: 1031-1048.

Ferreiro R. and P. Galan. 2004. Reproductive ecology of the slow worm (Anguis fragilis) in the northwest Iberian Peninsula. Animal Biology 54: 353-371.

Geiser, C., N. Ray, and A. Lehmann. 2013. Unraveling landscape variables with multiple approaches to overcome scarce species knowledge: a landscape genetic study of the slow worm. Conservation Genetics 14 : 783-794.

Gonzalo, A., C. Cabido, J. Martín, and P. López. 2004. Detection and discrimination of conspecific scents by the anguid slow-worm Anguis fragilis. Journal of Chemical Ecology 30: 1565-1573.

Gvozdík, V., D. Jandzik, P. Lymberakis, D. Jablonski, J. Moravec, and S. Ursenbacher. 2010. Slow worm, Anguis fragilis (Reptilia: Anguidae) as a species complex: genetic structure reveals deep divergences. Molecular Phylogenetics and Evolution 55: 460-472.

Hanski, I. 1994. A practical model of metapopulation dynamics. Journal of Animal Ecology 63: 151-162.

Hanski, I. 1999. Metapopulation Ecology. Oxford. Oxford University Press. 27 pp.

Hanski, I. and C. D. Thomas. 1994. Metapopulation dynamics and conservation - a spatially explicit model applied to butterflies. Biological Conservation 68: 167 180.

Kass, R. E. and A. E. Raftery. 1995. Bayes factors. Journal of the American Statistical Association 90: 773-795.
Kass, R. E. and L. Wasserman. 1995. A reference Bayesian test for nested hypotheses and its relationship to the Schwarz criterion. Journal of the American Statistical Association 90: 928-934.

Keribin, C. 2000. Consistent estimation of the order of mixture models. Sankhya, the Indian Journal of Statistics 62: 49-66.

Leroux, B. 1992. Consistent estimation of a mixing distribution. Annals of Statistics 20: 1350-1360.

Opdam, P. 1991. Metapopulation theory and habitat fragmentation: a review of Holarctic breeding bird studies. Landscape Ecology 5: 93-106.

Platenberg, R. 1999. Population ecology and conservation of the slow worm Anguis fragilis in Kent. Unpublished $\mathrm{PhD}$ Thesis. University of Kent, Canterbury, United Kingdom.

Platenberg, R. and R. Griffiths. 1999. Translocation of slowworms (Anguis fragilis) as a mitigation strategy: a case study from south-east England. Biological Conservation 90: $125-132$.

Reading, C. 1997. A proposed standard method for surveying reptiles on dry lowland heath. Journal of Applied Ecology 34: 1057-1069.

Riddell, A. 1996. Monitoring slow-worms and common lizards, with special reference to refugia materials, refugia occupancy and individual identification. Reptile Survey Methods 27: 46-60.

Ryan, M. 2008. Methods for estimating population size in the slow-worm Anguis fragilis and their practical application. Unpublished M.Sc. Dissertation. University of Bristol, United Kingdom.

Schwarz, G. 1978. Estimating the dimension of a model. Annals of Statistics 6: 461-464.

Schwarzkopf, L. and R. Shine. 1991. Thermal biology of reproduction in viviparous skinks, Eulamprus tympanum - why do gravid females bask more? Oecologia 88: 562569.

Shine, R. and P. Harlow. 1993. Maternal thermoregulation influences offspring viability in a viviparous lizard. Oecologia 96: 122-127.

Sumner, J. 2005. Decreased relatedness between male prickly forest skinks (Gnypetoscincus queenslandiae) in habitat fragments. Conservation Genetics 6: 333-340.

Sunnucks, P. 2000. Efficient genetic markers for population biology: single locus, co-dominant, yielding genealogies. Trends in Ecology and Evolution 15: 199-203. 
Smith, N. 1990. The ecology of the slow-worm (Anguis fragilis L.) in southern England. Unpublished $\mathrm{PhD}$ Thesis. University of Southampton, United Kingdom.

Stumpel, A. 1985. Biometrical and ecological data from a Netherlands population of Anguis fragilis (Reptilia, Sauria, Anguidae). Amphibia-Reptilia 6: 181-194.

Ter Braak, C. J. F., I. Hanski, and J. Verboom. 1998. The incidence function approach to modeling of metapopulation dynamics. Pp. 167-188 in J. Bascompte and R. V. Solé (eds.), Modeling Spatiotemporal Dynamics in Ecology. Springer.

Wapstra, E. 2000. Maternal basking opportunities affects juvenile phenotype in a viviparous lizard. Functional Ecology 14: 345-352.
Wapstra, E., T. Uller, G. While, M. Olsson, and R. Shine. 2010. Giving offspring a head start in life: field and experimental evidence for selection on maternal basking behavior in lizards. Journal of Evolutionary Biology 23: 651-657.

Zimmerman, K., Z. Fric, P. Jiskra, M. Kopeckova, P. Vlasanek, M. Zapletal, and M. Konvicka. 2011. Markrecapture on large spatial scale reveals long distance dispersal in the Marsh Fritillary, Euphydryas aurinia. Ecological Entomology 36: 499-510.

Editor: Philippe J. R. Kok 